\title{
Ways to implement aggressive motives and ideas of revenge in the context of experiencing high-intensity stresses
}

\author{
Aslanbek Saidov ${ }^{*}$, and Islam Khazhuev ${ }^{2}$ \\ ${ }^{1}$ CHSPU, psychology department, 364031, Grozny, Russia \\ ${ }^{2}$ CHSPU, SPPD department, 364031, Grozny, Russia
}

\begin{abstract}
The first part of the article provides a theoretical analysis of the study of the problem of PTSD, its impact on the development of various psychopathological reactions, as well as the role in the emergence of aggressive motives and ideas of revenge The results of empirical studies conducted at different times among the population of the Chechen Republic, which revealed the presence of a large number of examined posttraumatic disorders, are described separately. The second part presents the results of our own empirical study of the ideas of revenge and methods for their implementation, as well as the manifestations of various forms of aggressive behavior.
\end{abstract}

The high frequency and intensity of psycho-traumatic events taking place in different regions of the planet is accompanied by a significant increase in aggressive motives and ideas of revenge in people with traumatic past. Such traumatic experience leaves an indelible mark in the human psyche, and the images of the experienced extreme event are reflected in the assessments, perceptions and emotional experiences of both direct and indirect victims of psycho-traumatic impact.

As it is known, the psychological consequences of a psycho-traumatic event in its extreme manifestation are expressed in post-traumatic stress disorder (PTSD) [1]. The phenomenon of PTSD is a unique diagnosis characterized by the development of not only many forms of maladjustment and psychopathological reactions, but also a significant deterioration in the social, professional and psychological functioning of the individual.

Studies conducted in different countries with participants in various armed conflicts of the twentieth century gave a lot of information about both the PTSD and other accompanying psychopathological reactions [2-12]. According to the results of numerous studies, the psychological consequences of hostilities expressed in PTSD are diverse and often longer than peacetime PTSD. Since PTSD of military etiology, for combatants, as well as civilians forced to live in a zone of local armed conflict, is characterized by the many experienced horrors of war, violence, physical and mental stress, grief for loss, empathy for the wounded, etc. During hostilities, the participants in the conflict are constantly worried and alert, ready for aggressive actions against a real or imaginary enemy

\footnotetext{
* Corresponding author: aslsaidov@gmail.com
} 
(often innocent peaceful people playing the role). At the same time, the feeling of the value of human life and responsibility for one's aggressiveness is reduced. Civilians, on the contrary, are forced to under constant pressure from the warring parties, unlike the military, civilians are deprived of the opportunity to defend and attack, while experiencing high internal aggressiveness and feelings of revenge.

Features of the experience of post-traumatic stress is determined by the characteristics of the inner world of the personality and its reactions to experienced events. Along with the severity of distress, an individual's vulnerability to PTSD, a tendency to victimization, or fixation on traumatic experience also play an important role [1, 13].

According to numerous studies, individuals who survived traumatic events are much more likely to experience suicidal reactions [14-17, 13]. PTSD indicators largely coincide with the characteristics of suicidal personalities: depressed mood, loss of appetite, insomnia; alcohol or drug addiction; feeling of rejection or isolation; feeling of helplessness and hopelessness. Difficulties in communicating with people due to feelings of hopelessness and suicidal thoughts; "Tunnel vision" $[18,19]$. So, among veterans of the Vietnam War who have signs of PTSD from the end of the war and until 1990, more than 50 thousand committed suicide [18].

In explaining the formation of PTSD, the American Researcher M. Horowitz [20] focused on overloading the person with information and its incomplete processing. Since the traumatic experience is very significant and painful it cannot be immediately processed and as a result is deposited in the mind where it is stored in the so-called "active form of memory".

A similar point of view is shared by Russian researcher, leading specialist on the problem of PTSD in Russia, N.V. Tarabrina, which indicates that people with PTSD have impaired ability to integrate the traumatic experience with other life events. Due to the fact that traumatic memories remain unintegrated into the cognitive scheme of the individual and practically do not undergo changes over time - which is the nature of psychological trauma - the victim remains "frozen", fixed on the trauma as an actual experience, instead of accepting it as an event of the past. At the same time, traumatic memories exist in memory not in the form of coherent stories, but as intense emotions and somatosensory phenomena that are actualized when the suffering PTSD is in an excited state or when stimuli and situations remind of trauma $[1,13]$.

In addition, according to M. J. Horowitz and co-authors, post-traumatic stress, as well as other forms of stress, has active and passive manifestations. The active form of the stress response is characterized by inadequate aggressiveness and increased reactivity in situations associated with a traumatic event. And passive manifestations of the disorder are characterized by a predominance of individuals from psycho-traumatology avoidance of stimuli of trauma. [21, 22].

One of the consequences of post-traumatic stress is the high level of aggressiveness and the natural desire to punish the perpetrators, which is manifested in the form of a sense of revenge in persons with traumatized psyche.

According to Olshansky, psychologically, behind destructive behavior there is always an internal aggressiveness - an emotional state, which is based on anger and irritation arising as a reaction to frustration [23]. The author considers a terrorist act as a psychotraumatic event, which serves as a cause of increased tension in the form of increased aggressiveness, which requires discharge due to internal aggressive motives and feelings of revenge.

In various studies devoted to the problem of the growth of aggressiveness and the formation of ideas of revenge in the experiencing of PTSD, are given empirical data on their mutual coordination and greater susceptibility of persons with traumatic past aggressive motives and feelings of revenge. 
Thus, the study of 175 veterans of the fighting T. McHugh and co-authors [24] established reliable relationships between aggression and the severity of PTSD in the surveyed respondents. Of particular interest in this study is the strong correlation between the group of symptoms of excessive excitation in PTSD and aggression in patients both before and after treatment. Similar results indicating a correlation between PTSD and manifestations of aggression, anger and hostility among veterans of military operations in Afghanistan and the middle East were also revealed in the study of M. Jakupcak and coauthors [25].

At the same time, in a meta-analysis of B.G. Ciesielski and co-authors. [26] found that people with PTSD have significant difficulties in controlling anger and anger compared to people without PTSD and other anxiety disorders. A study by S. Lancaster and colleagues [27] found that negative emotional experiences such as anger, guilt, sadness, and disgust act as predictors of PTSD. The authors provide evidence of a positive relationship between the level of anger of the subjects and the severity of experiencing symptoms of PTSD.

A study of 174 victims of violent crime by Ulrich Orth and co-authors showed that the symptoms of two PTSD clusters - obsessive reproduction of trauma images and hyperexcitement are positively associated with a sense of revenge [28]. Similar results of the study are also given by M. Kunst [29], who revealed, based on a survey of a solid sample of subjects, reliable relationships between signs of intrusion and revenge in victims of traumatic events.

A study by Yaira Hamama-Raz et al. [30] of samples of Jewish and Israeli-Palestinian teenagers revealed that the latter, compared with their Jewish peers, are characterized not only by a greater susceptibility to experiencing post-traumatic symptoms, but also by a low ability to forgive and a high need for revenge. Although the two groups do not differ in levels of fear, the Israeli Palestinians are even more favorable to the world. We conducted a study of ways to implement aggressive motives and ideas of revenge among the psychotraumatic population of the Chechen Republic (ChR). This region is the most specific subject of the Russian Federation, as it was more than 13 years in a anthropogenic emergency, survived two brutal and bloody military campaigns, during which according to various estimates, killed from 150 to 200 thousand people, and thousands of people are still missing. For this reason, it is difficult to find a family in the Republic that did not experience wartime distress, individuals who did not directly or indirectly experience traumatic effects. The specificity of the region is also due to the historical, cultural and mental characteristics of the population - ethnic Chechens (many Chechens have their own history of the origin of the genus up to the 7 th tribe and almost all the indigenous population is interconnected by both close and distant family ties).

This ethnic group has a difficult history of development and differs from many other ethnic groups of Russia by the originality of cultural values, customs and traditions, one of which is the idea of revenge. Known facts, when the Chechens vendetta carried out even after 70 years. Another important feature of Chechens is their commitment to patriarchal values and their identification with the predominantly male part of the population, with the image of a warrior (A. Dyuma, L.N. Tolstoy, etc.). This statement is confirmed not only by the historical past (the great Caucasian war against Russia, numerous armed uprisings) but also by modern realities. The Republic is the most militarized region of Russia, and Chechen formations on a voluntary basis took part in almost all the armed conflicts of our time, which affected the interests of Russia, starting from South Ossetia and Abkhazia in Georgia and now in the Syrian Arab Republic. With the help of these groups, the Russian government also eradicated the terrorist underground in the Chechen Republic.

The results of empirical studies conducted at different times among the population of the ChR indicate high rates of PTSD prevalence in survivors of psycho-traumatic events. 
So, in a study conducted in 2002 (K.A. Idrisov), the clinical picture of PTSD was detected in $31.2 \%$ of the examined [31]. At the same time, in the study of H.B. Akhmedova, also conducted on residents of the Chechen Republic, PTSD indicators and adaptation disorders were detected in $42 \%$ [32]. And in a later study conducted in 20102011. post-traumatic stress corresponding to the clinical level of PTSD was detected in $22 \%$ of the examined residents of the Chechen Republic, while $30 \%$ of the respondents suffered from an average or subclinical level [33]. For comparison, it should be noted that in the study of veterans of the war in Afghanistan, conducted by the laboratory of posttraumatic stress SP RAS, it was found that only $17 \%$ of the surveyed combatants suffered from PTSD [13, 34, 35].

As shown in his study, H. B. Akhmedova, a significant part of the subjects from among the civilian population of the Chechen Republic, who survived the hostilities, were subject to the formation of a fanatical type of personality in PTSD.

The author has revealed that the fanatical variant of personality change reveals the relationship between the presence of PTSD in combination with the disorder of adaptation and the severity of alienation, isolation, suspicion, cruelty, straightforwardness, authoritarianism. As it turned out, personality changes after experiencing traumatic situations in $39.2 \%$ of cases led to the formation of the victims of the brutal events of the war rigid plants, reaching levels of overvalued ideas, in particular ideas of revenge. With the fanatical version of personality changes, the meaning of life also changed: in $77 \%$ of cases, revenge became the meaning of life, and in $32 \%$ of cases life did not make sense for the subjects [32].

Thus, the study of ways to implement aggressive motives and the idea of revenge in the context of experiencing high-intensity stress is a significant contribution to the solution of the problem not only to predict the possible pathological consequences of intense stress, but also to build effective work on the socio-psychological rehabilitation of victims of violence. The purpose of our empirical study was to study how to implement aggressive motives and ideas of revenge in the context of experiencing high-intensity stresses. The study involved 100 people aged 22 to 68 years. By gender, the sample was divided into $44(44 \%)$ men and $56(56 \%)$ women.

To achieve this goal, we have used the following research methods: clinical interviews of residents of the Chechen Republic, survivors of traumatic events of military etiology, including participants in the counter-terrorist operation and fighting among the employees of the Ministry of internal Affairs of the Russian Federation in the ChR with the help of a clinical and demographic map, which is used in the psycho-neurological clinic in Grozny to collect personal, demographic and socio-psychological data.

In the questionnaire we included questions aimed at identifying the presence of aggressive motives, ideas of revenge, as well as ways to implement them; the method "Types of aggressiveness" developed by L. G. Pochebut on the basis of the Buss-Durkey Inventory. The results of the clinical interview showed that $71 \%$ of the respondents experienced some form of psychological trauma.

Of these, $24 \%$ survived the death of a close relative, $22 \%$ - a life threat, $8 \%$ were injured, 3\% witnessed a violent death, $3 \%$ witnessed the destruction of a home, $2 \%$ survived the loss of relatives, $2 \%$ - a breakdown in marriage; $2 \%$ saw the abduction (in stripping), $1 \%$ was in the filtration camps. When asked whether you have ideas of revenge and the desire to harm or to take revenge on someone $77 \%$ said that they haven't any desire, $14 \%$ expressed poorly, but $3 \%$ of respondents said that they have a strong desire to take revenge.

Of all respondents, $15 \%$ answered that they managed to implement these ideas, $20 \%$ that failed, $7 \%$ still planning. Interesting results show the answers to the paragraph on how to implement the planned attempts of revenge. 1) $11 \%$ of the total number consider 
physical reprisals against the offender, $17 \%$ consider moral and psychological humiliation, $2 \%$ consider harming themselves on evil for others, $7 \%$ other variant.

Let's see, the results obtained using the method "Types of aggressiveness".

According to the type of verbal aggression, $30 \%$ of respondents have a high degree of aggressiveness, the rest are medium and low; A high degree of physical aggressiveness have $22 \%$ of the subjects; a high degree of subject aggression - $28 \%$; strong emotional aggression - $18 \%$; overstated self-aggression in $49 \%$ of respondents.

As we see in almost every type of external aggression, a third of the subjects have a degree of aggressiveness and a low degree of adaptability. However, a high level of internal aggression is observed in half of all respondents.

Concluding our research, we can draw the following conclusions:

1) Numerous studies conducted by various authors show that a person's long-term experience of traumatic events can cause the formation of various forms of aggressive impulses and ideas of revenge.

2) The results of the empirical study conducted by the authors showed that about a quarter of the subjects who have experienced to some extent a psychological trauma at least weak, but there is a desire to harm or take revenge on someone, and some even managed to implement them.

3) Also, as a result of the study, quite high rates of aggression were revealed. In almost every type of external aggression, a third of the subjects had a high degree of aggressiveness and a low degree of adaptability. However, a high level of internal aggression is observed in half of all respondents.

The work was supported by the grant Council of the President of the Russian Federation for the state support of young Russian scientists - candidates of Sciences (Competition - MK-2018) (MK2469.2018.6 "Ways to implement aggressive motives and ideas of revenge in the context of experiencing high-intensity stress").

\section{References}

1. N.V. Tarabrina, Workshop on psychology of post-traumatic stress (Piter, SPb, 2001)

2. T. P. Pallmeyer, E. B. Blancherd, L. C. Kolb, Bechev. Res. Ther., 24-6, 645-652 (1986)

3. D. W. Foy, E. M. Carroll, \& C. P. Donahoe, Journ. of Clinical. Psych., 43-1, 17-27 (1987)

4. H. R. Kormos, The nature of combat stress. In C. R. Figley (Ed.), Stress disorders among Vietnam veterans (Brunner/Mazel, New York, 1978)

5. B. J. Goderez, Journ. of Couns. and Dev, 65, 363-366 (1987)

6. J. A. Fairbank, R. A. Nickolson, Journ. of Clinical Psych., 43, 1, 44-63 (1987)

7. S.V. Litvintcev, Clinical and organizational problems of mental health care for military personnel in Afghanistan (Diss. of M.D., SPb., 1994)

8. E.B. Snedkov, Combat mental trauma (clinical and pathogenetic dynamics, diagnostics, treatment and rehabilitation principles) (Diss. of M.D., SPb., 1997)

9. E.M. Epanchintceva, Post-traumatic stress disorder in combatants (clinical - dynamic and rehabilitation aspects) (Diss. $\mathrm{PhD}$, Tomsk, 2001)

10. A. N. Kharitonov, G. N. Timchenko, Psychological assistance to families of professional servicemen (VU, Moscow, 2002)

11. T. B. Dmitrieva, V.G. Vasilyevsky, G.A. Rostovtcev, Rus. psychiatric journ., 3, 32-35 (2003)

12. V.G. Vasilyevsky, G. A. Fastovetc. Background and clinical and psychopathological features of post-traumatic stress disorder in combatants (PTSD, Moscow, 2005) 
13. N.V. Tarabrina, Psychology of post-traumatic stress: theory and practice (Moscow, 2009)

14. B. Kolodzin, How to live after a mental injury (Moscow, 1992)

15. A.G. Karayani, Psychological work in a combat situation (Samara, 1997)

16. A.G. Karayani, Psychological support of military operations of personnel of parts of land forces in local military conflicts (Moscow, 1998)

17. S.V. Dukhnovsky, Psychological support of teenagers in critical situations (Kurgan, 2003)

18. N.V. Yakushin, Psych. journ., 5, 66 (1996)

19. N.N. Pukhovsky. Psychopathological consequences of emergency situations (Akad. project, Moscow, 2000)

20. M.J. Horowitz, N. Wilner, N. Kaltreider, W. Alvarez, Arch. of Gen. Psychiatry, 37, 1, 85-92 (1980)

21. M. J. Horowitz, G. F. Solomon, Journ. of Soc. Iss., 31, 4, 67-80 (1975)

22. M.J. Horowitz, Hosp Comm. Psychiatry, 7 (1986)

23. D. V. Olshansky, Psychology of terrorism (Piter, SPb., 2002)

24. T. McHugh, D. Forbes, G. Bates, M. Hopwood, M. Creamer, Clin. Psychol. Rev., 32(1), 93-104 (2012)

25. M. Jakupcak, D. Conybeare, L. Phelps, S. Hunt, H.A. Holmes, B. Felker, M. Klevens, M.E. McFall, J Trauma Stress, 20, 6, 945-954 (2007)

26. B. G. Ciesielski, B. O. Olatunji, D. F. Tolin, Beh. Ther., 41(1), 93-105 (2010)

27. S. L. Lancaster, S. E. Melka, B. F. Rodriguez, Psych. Trauma: Theory, Research, Practice, and Policy, 3(4), 313-317 (2011)

28.U. Orth, L. Montada, A. Maercker, J Interpers Violence, 21, 2, 229-243 (2006)

29. M. J. J Kunst, Int. Jour. of Law and Psychiatry, 34(1), 362-367 (2011)

30. Y. Hamama-Raz, Z. Solomon, A. Cohen, A. Laufer, J. Traum. Stress, 21, 6, 521-529 (2008)

31. K.A. Idrisov, Vest. psychiatry and psychology of Chuvashia, 7, 21-34 (2011)

32. KH.B. Akhmedova, Personality change in post-traumatic stress disorder (according to the survey of civilians who survived the war) (Diss. Doctor of Psych., Moscow, 2004)

33. N.B. Tarabrina, I.S. Khazhuev, Exper. psych., 8, 3, 215-226 (2015)

34. M. E. Zelenova, Psych. journ., 18, 2 (1997)

35. M.A. Padun. Mental trauma and world view: Theory, experience, practice (Cogitocenter, Moscow, 2012) 